\title{
CASA DE ESCRAVO NA PAISAGEM MINEIRA: TEXTOS E IMAGENS
}

\author{
Juliana Prestes Ribeiro de Faria* \\ Marco Antônio Penido Rezende**
}

Resumo: Neste artigo trataremos da arquitetura africana produzida pelos escravos em Minas Gerais. Este tema será abordado na perspectiva da presença das moradias escravas na composição da paisagem mineira, através dos relatos de viagem que descrevem a vista destas habitações nas fazendas, nos arredores de povoados, arraiais e vilas, assim como nos assentamentos de empresas mineradoras, e da mesma forma nas pinturas dos artistas-viajantes que visitaram estas regiões. Estes aspectos se completam e demonstram o rico espectro que envolve a gênese e formação da arquitetura popular mineira e as contribuições africanas inerentes a este desenvolvimento.

Palavras-chave: Paisagem mineira. Literatura de viagem. Iconografia. Moradia escrava.

\begin{abstract}
The article proposes to treat the african architecture produced by slaves at Minas Gerais. This will be discussed in the perspective of the slave habitation presence in the composition of Minas Gerais landscape through travels writings that describes the view of these habitations in farms, surrounding the village and in the houses' settlement of the mining industry, and in the same way on the painting of travelling artists that visited those regions. These aspects complement each other and demonstrated the rich spectrum that involves the genesis and formation of Minas Gerais popular architecture and the african contributions inherent to this development.
\end{abstract}

Keywords: Minas Gerais landscape. Travels writing. Iconography. Slave habitation.

\footnotetext{
* Analista de gestão, proteção e restauro no Instituto Estadual do Patrimônio Histórico e Artístico de Minas Gerais. Professora do curso de especialização Lato Sensu da União de Ensino Superior de Minas Gerais (UESMIG). E-mail: juliana.prestes.faria@hotmail.com ** Professor Adjunto na Escola de Arquitetura da Universidade Federal de Minas Gerais (UFMG). E-mail: marco.penido.rezende@hotmail.com
} 
O trabalho escravo se constituiu como uma condição inerente ao desenvolvimento da economia e ao processo de colonização do Brasil. O negro era caracterizado como "os pés e as mãos" do senhor, fosse no trabalho doméstico, nas lavouras, nos engenhos, nas minas, os escravos tinham se tornado inteiramente indispensáveis já no fim do século XVI. ${ }^{1}$

Do mesmo modo se atribui à mão afro-brasileira a construção do Brasil urbano - com a edificação de parte significativa das residências, prédios oficiais, capelas, quartéis, pontes, chafarizes aquedutos e calçadas - realizada por escravos e forros e custeada tanto pelas autoridades régias e camarárias quanto pelas associações religiosas leigas como pela população civil. Os pedreiros, canteiros e carpinteiros que, juntamente com seus oficiais, aprendizes e serventes estiveram presentes nas obras públicas do Brasil colônia, eram genericamente denominados pelos portugueses de oficiais mecânicos, por fazerem uso das mãos em seu trabalho.

Por ganharem a vida com o esforço braçal, esses homens eram maculados com o defeito mecânico, que dentro da estrutura da antiga sociedade portuguesa os colocava em posição de inferioridade. ${ }^{2}$ Assim, os ofícios mecânicos e os trabalhos manuais não eram realizados pelos portugueses, pois eram vistos por estes como mais degradantes do que mendigar ou roubar. Este fato tornase evidente quando analisamos uma passagem da carta do governador do Rio de Janeiro à coroa, em 1726, onde ele ressalta que o trabalho nas minas só se fará possível com o emprego de mão-de-obra escrava "porque fazem serviço mais vigorozo, como porque os brancos, e Reynois, ainda que sejão criados com a enxada na mão, em pondo os pés no Brazil, nem hum quer trabalhar". ${ }^{3}$

Fica claro, assim, que o significado atribuído pelos portugueses ao trabalho manual privava-os do mesmo, o que nos leva a concluir que as intensas atividades construtivas urbanas só poderiam estar assentadas decisivamente no uso da mão-de-obra escrava. Além da presença no campo da execução de obras públicas, os escravos tiveram grande participação no âmbito da arquitetura popular, que corresponderia à construção do Brasil rural e urbano, mas na esfera civil. Sinteticamente tem-se que a análise da participação escrava na atividade construtora de todo o período colonial aponta-nos para o fato de que esta esteve presente desde a construção dos primeiros ranchos até a instituição de nossa arquitetura erudita.

O marco diferencial desta presença escrava nos canteiros de obras se estabelece justamente no nível de participação e, por conseguinte na escala de autonomia atribuída a esta mão-de-obra, já que nas obras públicas e de particulares a condição de impressão dos seus misteres construtivos seria inferior àquela utilizada na construção da sua própria moradia. Isso se deve ao fato de que a maioria dos projetos construtivos e ornamentais era desenvolvida em Portugal, sendo as plantas previamente fornecidas, assim como os materiais 
e alguns elementos arquitetônicos que vinham como lastro nos navios que saíam da metrópole rumo à colônia. Portanto, as evidências de uma arquitetura africana em solo brasileiro estariam definidas na própria constituição da habitação escrava e por isso esta será alvo de discussão.

A constatação de que determinadas tipologias arquitetônicas africanas, assim como os usos e as apropriações dos espaços, foram recriados nos quilombos mineiros, onde a autonomia dos escravos seria comprovadamente superior, é evidente. ${ }^{4}$ Contudo, estes não foram os únicos exemplares de matrizes arquitetônicas africanas em Minas Gerais, pois além dos quilombos podemos citar as moradias rurais dos escravos nas fazendas, nas circunvizinhanças de povoados, arraiais e vilas, e ainda nos assentamentos das empresas mineradoras. ${ }^{5} \mathrm{E}$ foram exatamente nestes mesmos espaços e nos respectivos momentos mencionados que a arquitetura popular mineira floresceu.

Se analisarmos os capítulos que compõem a formação da arquitetura popular em Minas Gerais, perceberemos que a habitação escrava esteve presente em todo o período no qual esta mão-de-obra foi empregada. Mas para chegarmos ao centro da discussão desta sessão, ainda cabe-nos um questionamento. As concepções e a execução destes espaços de moradia estavam sobre domínio dos próprios escravos ou de seus senhores? As pesquisas históricas que se ocuparam desta questão, apesar de tratarem de lugares e épocas variadas, vêm contribuindo para que os historiadores apontem para um consenso bem definido, "quando tiveram oportunidade para tanto, os escravos configuraram suas moradias baseando-se em formas e técnicas africanas". ${ }^{6}$

Assim, neste artigo, iremos correlacionar os aspectos característicos da arquitetura vernácula em Minas Gerais, descritos por Oliver em seu livro The encyclopedia of vernacular architecture of the world', com as descrições dos viajantes que apontam a presença das habitações escravas na constituição destes espaços. Desta forma será possível constatar que, em algumas situações, os senhores cuidaram pessoalmente da construção das habitações escravas, mas a regra parece ter sido a concessão de autonomia integral para os cativos erigirem esses espaços segundo sua cultura construtiva.

A publicação deste inventário da arquitetura vernacular mundial trás em suas páginas, Minas Gerais em três momentos históricos distintos. $\mathrm{O}$ primeiro se refere aos assentamentos originários da mineração do ouro, que durante o século XVIII floresceram em uma arquitetura religiosa suntuosa e uma arquitetura civil discreta e repetitiva, com fortes tradições ibéricas definidas por fachadas caiadas de branco e janelas pintadas com cores fortes. Até o início do século XX os métodos construtivos utilizados nestas regiões foram o adobe e o pau-a-pique. ${ }^{8}$

Nestes assentamentos, originários da mineração do ouro, ganham destaque os povoados, arraiais e vilas que se desenvolveram ao longo dos 
caminhos e nas áreas de mineração. A formação destes espaços e as exigências do próprio cotidiano urbano demandaram a presença de trabalhadores que desempenhassem as mais diversas modalidades de serviços manuais. As gravuras de Jean Baptiste Debret, que retratavam os escravos urbanos, forros e libertos do Rio de Janeiro, invariavelmente em uma posição de trabalho, apresentavam esta realidade reinante no Brasil, a de que "tudo assenta, pois, neste país, no escravo negro". ${ }^{9}$ Como consequencia da utilização desta mãode-obra nos centros urbanos de todo o Brasil no século XIX, teremos a presença permanente e massiva de negros, mulatos e mestiços e o posterior estabelecimento nestes espaços da moradia escrava.

Em Minas, a realidade não se apresentava diferente, pois até o último quartel dos Setecentos, as vilas eram habitadas em sua maioria por escravos, sendo que após este período ocorre a predominância de libertos e forros, o que nos leva a imaginar que o volume de edificações necessárias ao abrigo dos mesmos seria representativo. Estes últimos moravam cerca das vilas, como observado por Pohl em sua visita a Paracatu do Príncipe, onde ele avista que "em ambos os extremos da cidade, moram em maioria negros livres em cabanas, cujo aspecto anuncia a forte indigência dos donos". ${ }^{10}$

Também originários da mineração do ouro são os assentamentos das companhias mineradoras européias, principalmente britânicas e alemãs. Estas implantações foram realizadas com base na mão-de-obra escrava que executava processos produtivos mais avançados e distintos da produção agrícola. $\mathrm{O}$ grande exemplo da capitalização britânica na mineração brasileira é a Companhia St. John d'El Rey, fundada em 1830 por investidores londrinos através de uma concessão imperial de mineração, iniciando sua produção na mina de Morro Velho. ${ }^{11}$

As operações nesta mina eram divididas em sete departamentos, sendo um deste o dos negros, chefiado por um europeu e alguns feitores brasileiros que tinham sob sua tutela 1.690 escravos. Este departamento administrava o preparo e a distribuição de comida, a repartição de vestimentas e a inspeção das moradias dos cativos. Sobre as últimas, Libby ${ }^{12}$ esclarece que estas eram divididas em dois agrupamentos ou vilas de casas dotadas de um quintal com espaço para a criação de animais e uma horta, onde se estabeleciam os casais, ficando os escravos solteiros em grupos de dez a quinze pessoas alojadas em casas maiores.

$\mathrm{Na}$ visão de Richard Burton que visitou a Mina de Morro Velho em 1867, as construções do núcleo minerador e a vila dos escravos "se estendem da margem setentrional do Ribeirão até as elevações, a uma altitude de cerca de 150 metros; ali está o mais alto bairro negro, Timbuctoo, saudosa lembrança do que pode ter sido a terra natal, e aqui moram os negros de Cata Branca". ${ }^{13} \mathrm{~A}$ leitura da paisagem da vila dos escravos em Morro Velho é associada à imagem 
da cidade de Timbuctoo ${ }^{14}$ na África Ocidental, atestando certa similaridade entre as estruturas arquitetônicas visualizadas por Burton em suas viagens. Em face do exposto, é possível especular que algum nível de reprodução arquitetural existiu e foi permitida pelos ingleses, mas não fica evidente no relato se estas ocorreram no âmbito formal, técnico, simbólico ou ainda de uso e ocupação do solo.

A percepção de Mawe ${ }^{15}$ com relação à forma das casas dos escravos e da técnica construtiva utilizada por estes na edificação de seus abrigos em uma lavra próxima a Mendanha ${ }^{16}$, denota a mesma idéia de similaridade com as estruturas arquitetônicas da África (Figura 1).

Ai as casas, em número de cem, são isoladas e geralmente de forma circular, com tetos pontudos de palha, semelhantes às cabanas dos africanos, embora muito mais largas. As paredes formadas de estacas fincadas perpendicularmente na terra, entrelaçadas de ramos de árvores e rebocadas de barro por dentro e por fora. As casas dos oficiais são feitas dos mesmos materiais, mas de forma mais cômoda, sendo caiadas interiormente. Ao lado de algumas havia jardins cercados, o que animava a perspectiva, dando um ar de abastança a essas habitações simples e grosseiras. ${ }^{17}$

Para além da atuação das companhias britânicas de mineração tem-se a exploração em menor escala de minas como a Real Mina de Galena de Abaeté fundada pelo senhor Von Eschwege. ${ }^{18}$ Esta foi visitada por John Emmanuel Pohl que estando lá a descreve como um assentamento de mineração formado de doze cabanas que servem de morada aos negros e são edificadas em duas fileiras, uma casinha próxima que serve de morada ao senhor Eschwege e outra ao administrador da mina. 


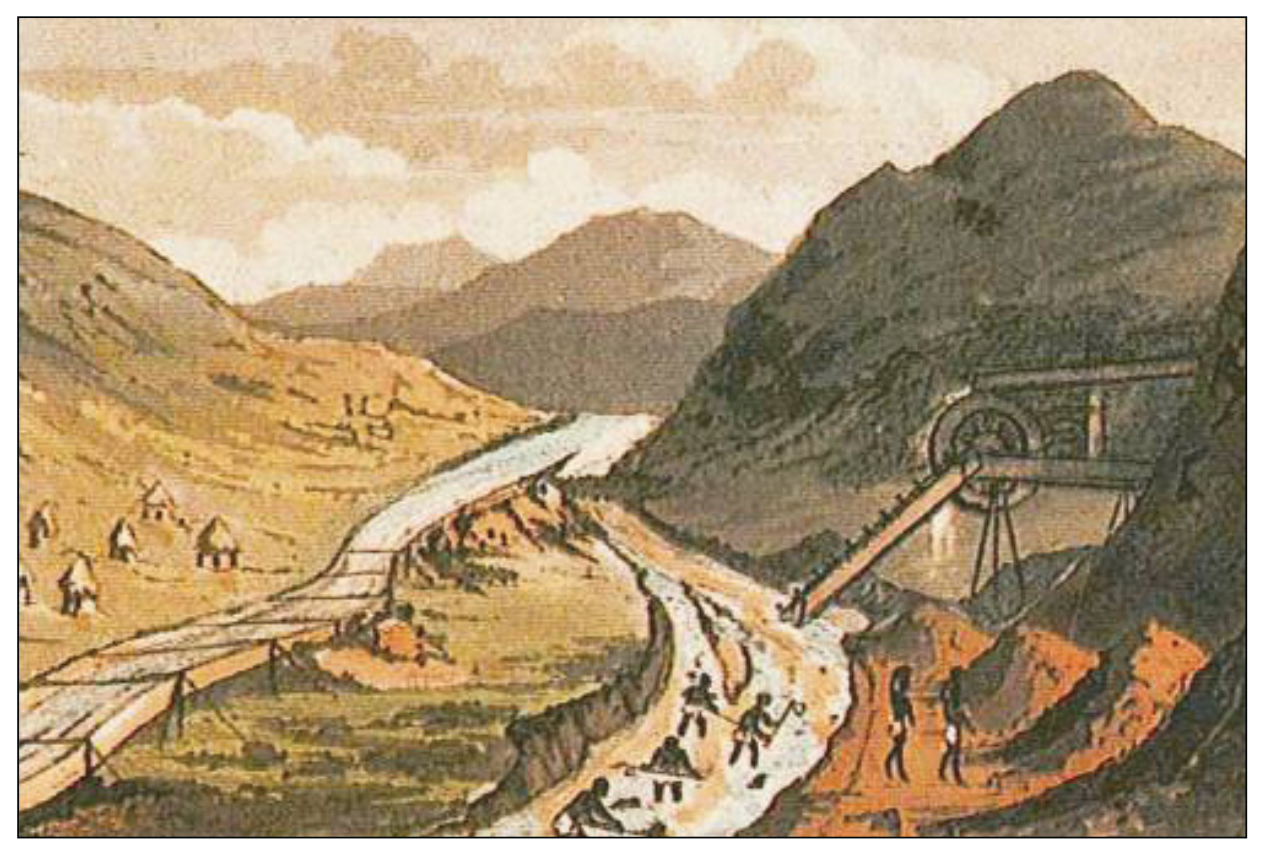

Figura 1 - "Busca de pedras preciosas num rio". A esquerda da figura estão representadas algumas moradias escravas, compondo a paisagem das áreas de exploração de ouro de Minas Gerais. Fonte: MAWE, John. Viagens ao interior do Brasil. São Paulo: USP; Belo Horizonte: Itatiaia. 1978. 243 p.

Aproxima-se desta descrição a foto de Augusto Riedel ${ }^{19}$ tirada em 1868 em sua visita a lavra de diamantes do senhor Vidigal no rio Jequitinhonha em Minas Gerais (Figura 2). Em primeiro plano aparecem os trabalhadores da lavra e os seus senhores, ficando em segundo plano as estruturas de retirada do cascalho, e um grupo de pequenas habitações que, pela proximidade da área de exploração, tipologia e disposição de uma em relação às outras, parece-nos as habitações dos escravos empregados no trabalho de mineração.

Se aumentarmos o foco de visualização sobre este pequeno assentamento, iremos perceber que as casas estão dispostas alternadamente sob reduzidos platôs, e que estas se constituem de plantas retangulares, com coberturas duas águas em materiais vegetais e estrutura em terra crua (Figura 2). Além disso, nota-se a existência de uma porta frontal, que em uma das casas está posicionada do lado esquerdo e na outra do lado direito ${ }^{20}$, sendo esta a única abertura da moradia. A inexistência de janelas nas construções africanas do Brasil, também foi constatada por Pohl, quando este viajante chegou a Farinha, uma aldeia de negros, "de quinze cabanas sem janelas que só recebem luz pelas portas". ${ }^{21}$ Esta característica é encontrada dos dois lados do Atlântico, já que nas construções da África, na maior parte das vezes, há a presença de uma só porta como única abertura. 

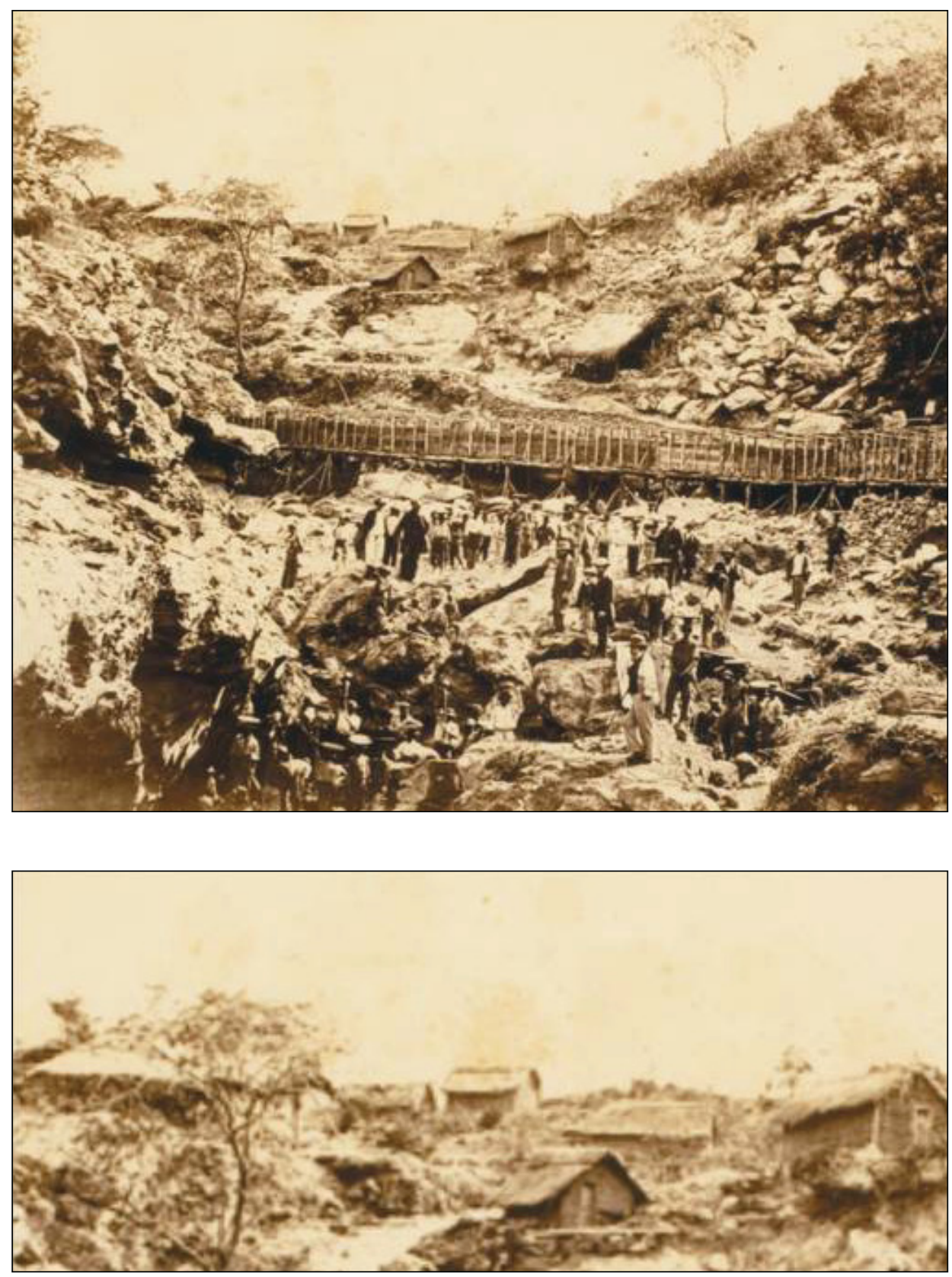

Figura 2 - Lavra de diamantes do senhor Vidigal no rio Jequitinhonha (tiragem de cascalho). Fotografia de Augusto Riedel, 1836. Fonte: Biblioteca Nacional Digital. Disponível em: <http://bndigital.bn.br/scripts/odwp032k.dll?t=nav\&pr=fbn dig_pr\&db=fbn_dig\&use $=$ cs0\&rn $=1 \&$ disp $=$ card\&sort $=$ off $\& s s=22743502 \& \mathrm{a}$ rg=vidigal $>$. Acesso em: 18 maio 2011. 
A ausência de janelas nas construções é atribuída à cultura banta segundo Weimer ${ }^{22}$, entretanto Slenes argumenta que esta pode ser explicada em primeiro caso por uma decisão dos cativos em se utilizarem dos mesmos padrões das construções africanas, ou ainda por limites de tempo, de material e de desenho arquitetônico impostos pelos senhores, ou até com o intuito de impedir fugas. Entretanto, esta poderia se dar tanto pela porta como pela janela, a menos que estas fossem trancadas pelos senhores de noite. De qualquer forma, nesse evento, "a imposição teria coincidido com as preferências dos escravos, ou pelo menos com as preferências iniciais dos cativos africanos. Estes, sem dúvida, se calaram para aproveitar-se da situação". ${ }^{23}$

Para além da exploração aurífera das lavras, que exigia a disponibilidade de ferramentas e um número expressivo de mão-de-obra escrava, Minas Gerais foi o grande palco do trabalho de faiscação, representada pela pequena extração realizada por alguns poucos garimpeiros. A literatura de viagem descreve inúmeros lugarejos que se formaram próximos destas pequenas áreas de exploração, sendo este cenário comum aos fins do século XVIII, quando a mineração entra num processo de franca decadência. As lavras, faisqueiras e catas, quando descobertas, eram invariavelmente habitadas temporariamente ou permanentemente, sendo que estes assentamentos poderiam ter um número reduzido de moradias - como a povoação de Garo visitada por Pohl ${ }^{24}$, onde viviam negros que extraiam ouro da argila vermelha da região, formada de oito choupanas de barro - assim como os grandes assentamentos das empresas mineradoras de capital estrangeiro.

Desta forma, demonstramos que os assentamentos originários da mineração do ouro e, logicamente, as habitações dos escravos que constituíam estes, foram presença marcante na paisagem mineira, sendo descritas pelos viajantes que estiveram em Minas Gerais e, em alguns casos, reproduzidas nas pinturas dos artistas-viajantes e fotógrafos do período.

Continuando nesta linha de pensamento, temos que as vilas foram os centros sociais e econômicos da província de Minas Gerais durante todo o século XVII e XVIII. Em contraposição, as áreas rurais ganharam importância apenas no fim do século XIX com o aumento da produção agrícola e da pecuária, promovendo na paisagem mineira o surgimento das fazendas com suas casasgrande e ao longe as casas dos trabalhadores livres. Este segundo momento é relativo à arquitetura rural, que ostenta os sinais da tradição vernácula, refletida em influências portuguesas, escravas e indígenas, com plantas retangulares, varanda ao longo de toda a fachada seguida por uma série de janelas e capelas que reafirmam a tradição religiosa do povo português. ${ }^{25}$ A estrutura autônoma de madeira com fechamentos em pedra, adobe ou taipa caracterizam as técnicas construtivas utilizadas nas propriedades. ${ }^{26}$ 
As fazendas da região mineradora aparecem na paisagem de Minas Gerais com a descoberta do ouro e o consequente aumento da população, que geraram o crescimento da demanda por alimentos e o surgimento destas propriedades agrícolas pelos caminhos. Estas inúmeras chácaras, roças, engenhos e estâncias se distinguiam pelos tipos de cultura que produziam, pelos rebanhos de animais que criavam e, finalmente, pelos processos mecânicos (serrarias, moendas, máquinas de beneficiar arroz e café, alambiques de aguardente de cana, etc.) que desenvolviam. Estas se assemelham em um aspecto, todas se constituem das mesmas estruturas: residência do senhor, as instalações, e as "cabanas habitadas pelos negros" que trabalhavam e moravam nestas terras.

As fazendas em Minas Gerais e a presença das habitações escravas na constituição destas propriedades foi bem documentada nos relatos de viagem de Pohl. Citaremos algumas das inúmeras referências feitas pelo viajante, iniciando com a da grande fazenda João do Vale, "que é construída sobre um morro juntamente com uma casa de residência e vinte choupanas de negros". ${ }^{27}$ Pohl também cita a Fazenda Santa Cruz de Dona Teresa, que fica próxima de Tijuco, e consiste "numa casa residencial assobradada, várias casinhas anexas e cabanas de negros". ${ }^{28}$ E até, a propriedade do capitão-mor do distrito de Sabará, senhor Felício Luis Pinto Coelho, a fazenda da Cachoeirinha, que consiste numa "casa assobradada com espaçoso pátio, cercada de habitações de negros". ${ }^{29}$

Para além dessas citações, e talvez mais importante, seria encontrarmos as descrições dos viajantes acerca de como os escravos usavam os espaços internos de suas moradias. Entretanto, estes não se preocupavam em decifrar esse significado, insistindo em resumir os espaços às palavras "cabanas", "choças" e "choupanas". Com relação ao uso do espaço externo, que compreendia as imediações do conjunto de habitações escravas, John Luccock coloca que na fazenda de Pedro Alves, entre as choças de negros reinava a máxima ordem e decoro, que uma estrita disciplina mantinha, mas que "apesar disso, pareciam todos felizes: as crianças brincavam a pequena distância da casa, enquanto que as pessoas de mais idade formavam um grupo de observadores; os escravos capazes estavam diligentemente ocupados e não se via doença alguma". ${ }^{30} \mathrm{~A}$ leitura desta passagem nos instiga a dar outra dimensão as palavras "cabanas", "choças" e "choupanas", a de que estes se constituíam em "lares", onde a vida cotidiana acontecia. ${ }^{31}$

Devido às limitações das fontes, como já vimos, recorreremos à iconografia para apresentar a possível tipologia arquitetônica destas habitações escravas nas fazendas. A obra Voyage Pittoresque et Historique au Brésil ${ }^{32}$ de Debret contém em suas páginas uma prancha com a gravura intitulada "Feitores castigando negros" que nos apresenta em primeiro plano os tipos de castigos aos quais os escravos estavam sujeitos nas fazendas de café (Figura 3). De 
acordo com a descrição do pintor ${ }^{33}$, a cena representa uma roça, tendo à direita a residência do feitor onde aparecem apenas os degraus da varanda, e ao fundo à beira de um riacho estão às choças dos negros, enquanto que acima deste plano há um canavial e colinas cobertas de cafezais. As choças dos negros que aparecem como pano de fundo da pintura revelam uma tipologia já apresentada, a da casa com planta retangular ou quadrada, cobertura vegetal e uma única porta como abertura privando a mesma do emprego de janelas. Em suma, há indícios de que as habitações escravas nas fazendas mineiras eram similares àquelas encontradas nos mais diversos tipos de assentamentos constituídos pela mineração, e anteriormente apresentados.

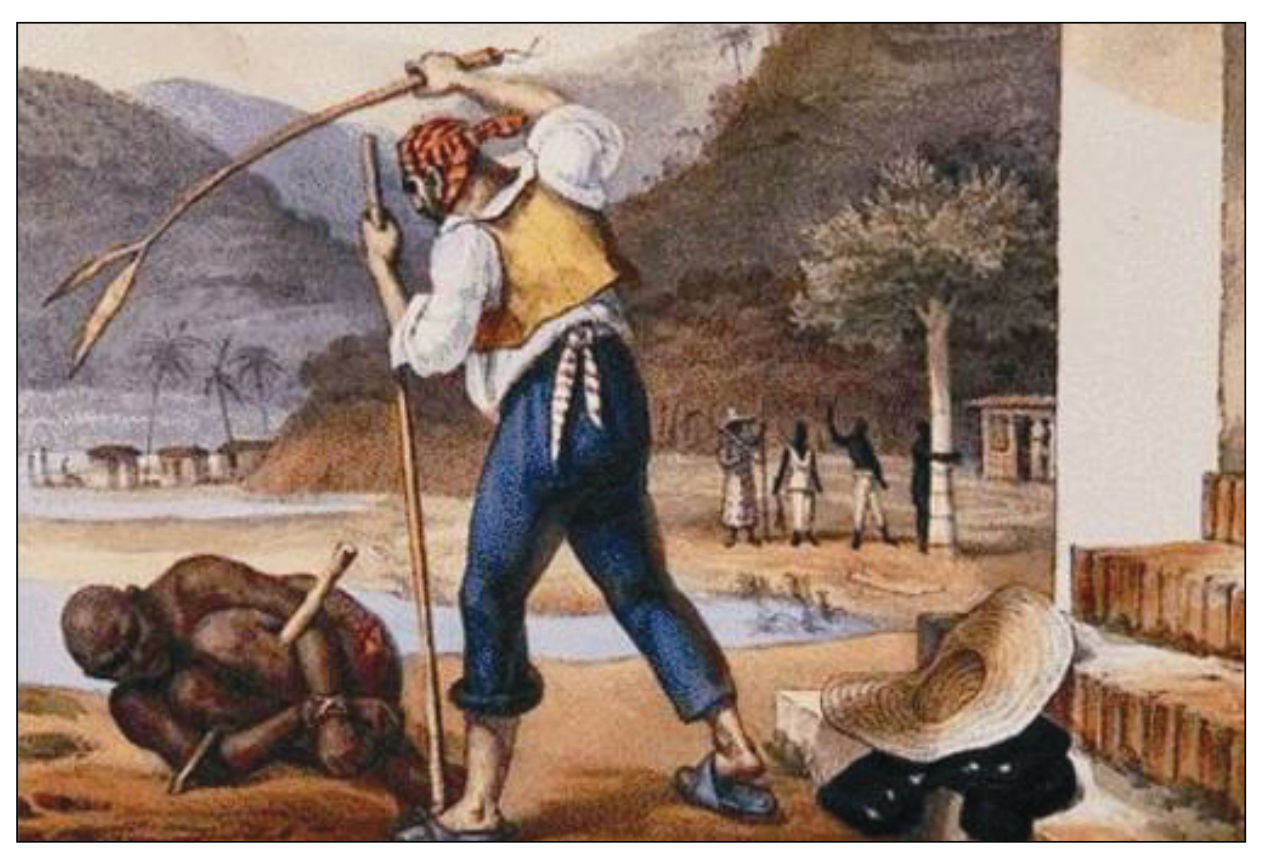

Figura 3 - Feitores castigando negros. Ao fundo estão representadas as choças dos escravos.Fonte: Biblioteca Digital Brasiliana USP. Disponível em: $<$ http://www. brasiliana.usp.br/bbd/ handle/1918/624520069>. Acesso em: 22 maio 2011.

Após o todo apresentado, colocamos que ao que parece as propriedades e os seus conjuntos de moradias escravas fizeram parte da extensa paisagem mineira cursada pelos viajantes. Saint-Hilaire atesta este fato, quando descreve ao longe as terras por ele percorridas em Minas Gerais e o prazer que teve em suas andanças, "esta alternativa de cafezais e matas virgens, roças de milho, capoeiras, vales e montanhas, esses ranchos, essas vendas, essas pequenas habitações rodeadas das choças dos negros e as caravanas que vão e vem, dão aos aspectos da região grande variedade. É agradável percorrê-la". ${ }^{34}$ Da mesma 
forma, que as habitações escravas construídas nos assentamentos da mineração, se compunham com as paisagens das áreas de exploração.

Assim sendo, recapitular a trajetória da moradia escrava em Minas Gerais demonstrou uma sucessão de episódios que culminaram em algumas afirmativas. Iniciamos pelo fato de que os escravos estavam em número expressivo e desempenhando os mais distintos tipos de trabalhos manuais. A presença desta mão-de-obra criou a necessidade de abrigo e a consequente construção de habitações, que foi notada pelos viajantes tanto nas fazendas, assim como nos assentamentos da mineração. Pelo nível de autonomia construtiva dada a estes escravos na edificação de suas moradias é de se supor que o emprego de saberes e fazeres particulares a estes povos foi proeminente.

Os escravos mineiros quando tiveram o pleno controle do processo de construção puderam produzir estruturas que eram formalmente distintas das de seus senhores. Mas quando estas oportunidades foram severamente talhadas pela instituição da escravidão, as moradias construídas pelos negros manifestaram apenas traços de sua cultura, apresentando como resultado moradias que detinham um leve grau de diferença da cultura arquitetônica dominante. "Entretanto, até quando um traço cultural só é sutilmente manifestado, não é menos significante". ${ }^{35}$ Os traços que identificamos como possíveis reflexos da impressão da cultura construtiva africana em solo mineiro estão ligados à volumetria das edificações, aos tipos de planta retangulares e quadradas, a inexistência de janelas, ao pé direito da edificação e ao tipo de cobertura, duas águas.

Dentro dessa perspectiva a "casa de mocambo" (Figura 4) identificada por Freyre ${ }^{36}$ se assemelha em grande parte as moradias escravas descritas, pois compartilham traços que parecem seguir uma seqüência evolutiva, como colocado por Weimer:

\footnotetext{
Aimigração ${ }^{37}$ teve por principal conseqüência a simplificação e diminuição das tipologias arquitetônica. A forma hegemônica entre os bantos de construção de "cone-sobrecilindro" praticamente desapareceu e foi substituída pela do "mocambo". [...] Por outro lado, as construções africanas preponderantemente monofuncionais deram lugar as plurifuncionais como resistência à multifuncionalidade das construções do colonizador. Se as construções na África tinham, na maior parte das vezes, uma só porta como abertura, aqui as janelas - ainda que pequenas - mostram hoje terem sido amplamente aceitas. ${ }^{38}$
} 


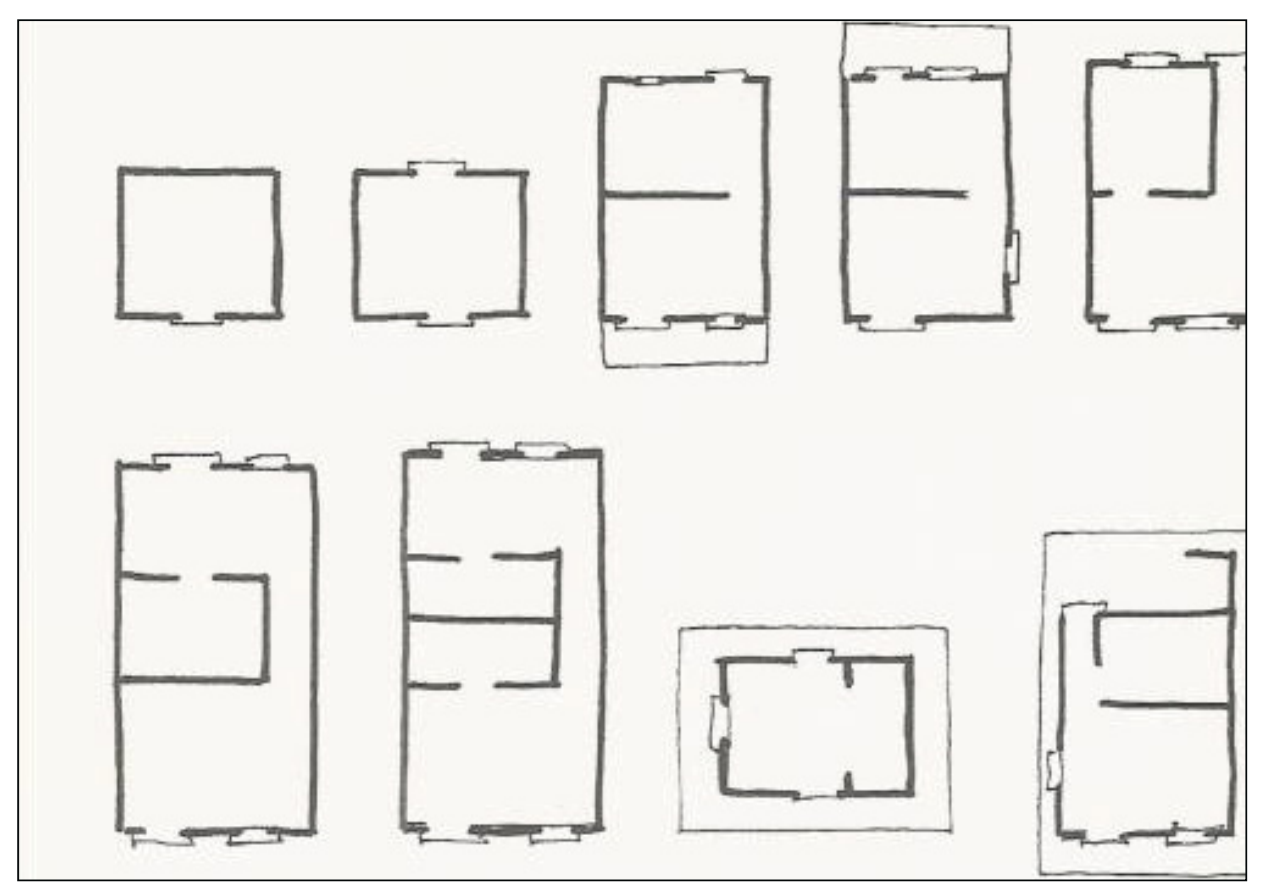

Figura 4 - Esquema da variabilidade das plantas baixas das casas dos imigrantes negros. Fonte: Instituto Histórico e Geográfico do Rio Grande do Sul. Disponível em: <http:// www.ihgrgs.org.br/artigos/Gunter_Brasil_Africa.htm>. Acesso em: 30 maio 2011.

Esta nos parece ser uma tipologia desenvolvida e adaptada ao constante contato dos repertórios materiais e culturais de negros e brancos, e que foi adotada e efetivamente incorporada dentro das práticas populares de construção. Para Oliver ${ }^{39}$, esses conhecimentos técnicos construtivos irão se materializar, no terceiro momento histórico arquitetônico de Minas Gerais, que compreende todo o período de seu desenvolvimento urbano. No século XX, grande parte dos trabalhadores livres das fazendas migrou para as cidades, criando assim uma camada social com restrito acesso ao mercado de trabalho devido ao baixo nível de escolaridade. Estes trouxeram consigo, como patrimônio da cultura rural, as suas formas e técnicas construtivas tradicionais, que se caracterizam por plantas quadradas ou retangulares sem divisões internas e uma estrutura autônoma de madeira com fechamentos em adobe, taipa ou pedra, assim como ocorre na arquitetura rural. Assim, o autor conclui que as moradias da periferia das cidades são remanescentes da era colonial, refletindo uma tradição cultural que se iniciou há três séculos.

O significado deste postulado cultural não pode ser negligenciado, pois representa uma importante contribuição dos afro-brasileiros para a nossa arquitetura popular e consequentemente para a constituição da paisagem cultural mineira. A importância destes traços, como argumentado por Vlach ${ }^{40}$ ainda vai além, pois, de fato, os escravos estiveram aptos, com o mínimo de 
condições materiais disponíveis, a criar uma paisagem residencial e de trabalho que traduzia de alguma forma a sua cultura, sendo que esta não é menos significativa que aquela desenvolvida pelos homens livres brancos.

\section{CONSIDERAÇÕES FINAIS}

O trabalho escravo nas áreas urbanas e nas propriedades rurais permitia um contato de elevado grau de proximidade com a cultura do colonizador, lhes facultando um nível superior ao dos quilombos tanto de influência como de menor autonomia sobre a concepção dos espaços de moradia de acordo com seus padrões construtivos. Apesar disso a moradia escrava nas fazendas mineiras, nas proximidades das vilas e nos assentamentos das empresas mineradoras, que estão descritas na literatura de viagem e retratadas pelos artistas-viajantes do século XIX, irão se revelar um modelo que não esconde filiação com tipologias arquitetônicas africanas. As várias correspondências se resumem a forma retangular sem compartimentação interna que se configura em um volume simples, a cobertura duas águas com materiais vegetais, a ausência de janelas e a presença de uma porta como entrada única e finalmente a baixa altura da edificação.

Fica evidente que os conceitos foram importados da África Ocidental com a idéia de que esta forma e uma série de práticas ligadas a esta eram consideradas adequadas à nova situação aos quais os africanos estavam submetidos. As mesmas preferências espaciais que tinham na África certamente foram inclusas a sua moradia no Brasil, já que a memória construtiva africana guiou as escolhas e percepções da experiência escrava. Ou ainda se analisarmos por uma perspectiva cética, caso esta tipologia tenha sido o resultado de imposições feitas pelos senhores assim como de sua influência então esta atendeu, de qualquer forma, tanto as expectativas dos escravos como as necessidades dos senhores.

Se percorrermos os caminhos da história desta tipologia arquitetônica perceberemos que este modelo recebeu modificações morfológicas relevantes, mas manteve seus conceitos essenciais. As alterações, entretanto, não a excluíram de nossa paisagem, pelo contrário, foram exatamente estas adaptações arquitetônicas que a fundiram definitivamente e a fizeram parte constituinte de nossa arquitetura popular e desta forma de nossa paisagem cultural. As superposições das sucessivas cenas descritas e retratadas pelos viajantes permitiram que visualizássemos os primórdios da aparição desta tipologia que permanece em nossa paisagem até os dias atuais. 
Os africanos responderam arquitetonicamente a escravidão de forma a adaptar em nível espacial, material e social uma determinada tipologia a um novo ambiente físico e cultural, com o intuito de que este se assemelhasse a um padrão familiar, assim seria possível estabelecer o envolvimento destes com a sua moradia em um país ainda desconhecido. A reação à adversidade foi tenazmente conservadora tendo em vista que o contato dos africanos com uma nova cultura não promoveu necessariamente uma mudança radical nas concepções de sua arquitetura, mas sim alterações arguciosas.

\section{NOTAS}

${ }^{1}$ BOXER, C. R. A idade de ouro do Brasil: (dores de crescimento de uma sociedade colonial). São Paulo: Comp. Ed. Nacional, 1969.

${ }^{2}$ GODINHO, Vitorino Magalhães. Estrutura da antiga sociedade portuguesa. 3 ed. Lisboa: Editora Arcádia, 1977. p. 71-116.

3 BOXER, op. cit., p. 189.

${ }^{4}$ Ver: FARIA, Juliana Prestes Ribeiro de. Influência Africana na Arquitetura de Terra em Minas Gerais. 2011. 160 f. Dissertação (Mestrado em Ambiente Construído e Patrimônio Sustentável) - Escola de Arquitetura, Universidade Federal de Minas Gerais, Belo Horizonte, 2011.

${ }^{5}$ Cabe ainda esclarecer que só serão analisadas as tipologias de moradia isolada dos escravos africanos, tanto nas propriedades rurais como nas proximidades das vilas. Essa distinção faz-se necessária, pois existem outros tipos de habitação escrava, como as senzalas e as enxovias, que devido ao seu nível de especificidade não foram tratadas por esta pesquisa.

${ }^{6}$ MARQUESE, Rafael de Bivar. Moradia escrava na era do tráfico ilegal: senzalas rurais no Brasil e em Cuba, c. 1830-1860. Anais do Museu Paulista, São Paulo, v. 13, n. 2, 2005, p. 166.

${ }^{7}$ OLIVER, Paul. Encyclopedia of vernacular architecture of the world. Cambridge; New York, NY, USA: Cambridge University Press, 1997. 2384 p.

8 Ibidem.

9 DEBRET, Jean Baptiste. Viagem pitoresca e histórica ao Brasil. Belo Horizonte: Ed. Itatiaia; São Paulo: EDUSP, 1989. p. 16.

${ }^{10}$ POHL, Johann Baptist Emanuel. Viagem no interior do Brasil: empreendida nos anos de 1817 a 1821 e publicada por ordem de sua majestade o imperador da Áustria Francisco Primeiro. Rio de Janeiro: Instituto Nacional do Livro, 1951. 2 v., p. 239.

${ }^{11}$ LIBBY, Douglas Cole. Trabalho escravo e capital estrangeiro no Brasil: o caso de Morro Velho. Belo Horizonte: Itatiaia, 1984. 158 p.

${ }^{12}$ Ibidem.

${ }^{13}$ BURTON, Richard Francis. Viagem do Rio de Janeiro a Morro Velho. São Paulo: EDUSP, 
1976. p. 193 e 194. (Coleção Reconquista do Brasil, 36).

${ }^{14}$ Timbuctoo é uma cidade da região de Tombouctou, na África Ocidental nação de Mali, que no século XV e XVI era a capital intelectual e espiritual e centro de propagação do Islã na África. Essa região do império de Mali era um entreposto comercial que ligava a África Ocidental com o mundo árabe, e por isso sofreu grande influência dos bárbaros. Segundo Vélez Jahn (2005) Timbuctu surge das areias do deserto como um a miragem de formas de barro. Sua estrutura urbana e suas ruas arenosas dialogam com a eternidade. Cinco bairros repartem-se no espaço urbano rodeado por uma muralha de cinco quilômetros, que se mesclam na paisagem, com as mesquitas de Djingareiber, de Sankoré e de Sidi Yéhia.

${ }^{15}$ MAWE, John. Viagens ao interior do Brasil. São Paulo: USP; Belo Horizonte: Itatiaia. 1978. $243 p$.

${ }^{16} \mathrm{O}$ viajante destaca que esta é a maior exploração de diamantes e está situada a trinta milhas no Rio Jequitinhonha, na qual trabalham mil negros em certas ocasiões dois mil.

${ }^{17}$ MAWE, op. cit., p. 154 e 155.

${ }^{18}$ O Barão de Eschwege veio ao Brasil a serviço da corte de Dom João VI e em Minas Gerais se instalou para realizar um levantamento das riquezas mineralógicas. Além de desempenhar as funções de funcionário público, este supervisionou os trabalhos de três empreendimentos: a instalação da fabrica Patriótica, em Congonhas do Campo, a mina de chumbo no sertão de Abaeté, e ainda, a mina de Passagem, localizada entre Ouro Preto e Mariana. (GOMES, Francisco Magalhães. História da siderurgia no Brasil. Belo Horizonte: Itatiaia; São Paulo: Editora da Universidade de São Paulo, 1983. 409 p.).

${ }^{19}$ Augusto Riedel, fotógrafo alemão autor do álbum intitulado Viagem de S. S. A. A. Reaes Duque de Saxe e Seu Augusto irmão Luiz Philippe ao interior do Brazil, que congregava as fotografias realizadas durante a viagem do genro do imperador Pedro II, Dom Luis Augusto de Saxe Coburgo e Gotha, marido da princesa Leopoldina, às províncias de Minas Gerais, Bahia e Alagoas em 1868. (VASQUEZ, Pedro Karp. A fotografia no Império. Rio de Janeiro: Jorge Zahar Ed., 2002).

${ }^{20}$ Weimer (2008) coloca que entre os sudaneses era largamente hegemônica o uso da porta à direita da entrada do "mocambo" ao contrário dos bantos, que em via de regra, a colocavam a esquerda.

${ }^{21}$ POHL, Johann Baptist Emanuel. Viagem no interior do Brasil: empreendida nos anos de 1817 a 1821 e publicada por ordem de sua majestade o imperador da Áustria Francisco Primeiro. Rio de Janeiro: Instituto Nacional do Livro. 1951. 2 v., p.187.

${ }^{22}$ WEIMER, Günter. Inter-relações arquitetônicas Brasil-África. 2008. 40 p. Pronunciamento de Posse como membro efetivo do IHGRGS. Porto Alegre. Disponível em: $<$ http://www.ihgrgs. org.br/artigos/Gunter_Brasil_Africa.htm>. Acesso em: 25 mar. 2010.

${ }^{23}$ SLENES, Robert W. Na senzala, uma flor: esperanças e recordações na formação da família escrava - Brasil Sudeste, século XIX. Rio de Janeiro: Nova Fronteira, 1999. p. 166.

${ }^{24}$ POHL, op. cit.

${ }^{25}$ OLIVER, Paul. Encyclopedia of vernacular architecture of the world. Cambridge. New York, NY, USA: Cambridge University Press, 1997. 2384 p.

${ }^{26}$ A arquitetura rural mineira, citada por OLIVER (1997), foi amplamente discutida em: MENEZES, Ivo Porto de. Fazendas Mineiras. Escola de Arquitetura da UFMG, 1969; 
VASCONCELLOS, Sylvio de. Arquitetura: dois estudos. Porto Alegre: Instituto Estadual do Livro, 1960; MELLO, Suzy. Barroco Mineiro. São Paulo: Brasiliense, 1983.

${ }^{27}$ POHL, op. cit., p. 191.

${ }^{28}$ Ibidem, p. 359.

${ }^{29}$ Ibidem, p. 377.

${ }^{30}$ LUCCOCK, John. Notas sobre o Rio de Janeiro e partes meridionais do Brasil. Belo Horizonte: Itatiaia; São Paulo: Editora da Universidade de São Paulo, 1975. p. 359.

${ }^{31}$ Slenes (1999) explora a perspectiva dos lares negros e de todas as estratégias familiares que permearam as condições de cativeiro.

32 "O primeiro volume apresenta os selvagens e os aspectos das florestas; o segundo volume detêm-se genericamente nas modalidades de trabalho agrário, na presença do negro escravo e do pequeno artesão urbano; e o terceiro abrange a esfera pública dos usos e costumes populares, acontecimentos políticos e outras práticas culturais do Rio de Janeiro, assim como os hábitos domésticos". (BELLUZZO, Ana Maria de Moraes. O Brasil dos viajantes. São Paulo: Metalivros; Odebrecht. 3 v., 1994, p. 84).

${ }^{33}$ Os desenhos de Jean Baptiste Debret foram posteriormente inscritos na lógica narrativa da Voyage Pittoresque et Historique au Brésil sendo as pranchas descritas sinteticamente pelo viajante.

${ }^{34}$ SAINT-HILAIRE, Auguste de. Segunda viagem do Rio de Janeiro a Minas Gerais e a São Paulo, 1822. Belo Horizonte: Itatiaia; São Paulo: USP, 1974. p. 100.

${ }^{35}$ VLACH, John Michael. By the work of their hands. Virginia: University Press of Virginia, 1991. p. 182.

${ }^{36}$ FREYRE, Gilberto; ANDRADE, Carlos Drummond de; BANDEIRA, Manuel; REGO, José Lins do; DIAS, Cícero; Poti. Casa-grande \& senzala: formação da família brasileira sob o regime da economia patriarcal. 32 ed. Rio de Janeiro: J. Olympio, 1992. 569 p.

${ }^{37}$ A emigração forçada dos africanos para a América e o contato com uma sociedade diferente fez com que as novas organizações sociais afro-americanas e afro-brasileiras, em particular, tivessem de se reordenar de modo bastante diferente das tradicionais. Adquiriram, portanto, características peculiares que podem ser especificadas - dentro da perspectiva dos objetivos da arquitetura - com as seguintes características: a) uma generalizada homogeneização por via da destribalização; b) a família poligâmica foi substituída - pelo menos, oficialmente pela monogâmica; c) as diversas culturas regionais africanas tiveram de se readaptar a um meio multicultural; d) a manutenção de fatores culturais africanos só foi possível através de adaptações a novas condições interativas dos diversos grupos formadores; e) devido às condições em que se processou esta imigração, a religião acabou por se consolidar como principal suporte da africanidade. (WEIMER, Günter. Inter-relações arquitetônicas BrasilÁfrica. 2008. 40 p. Pronunciamento de posse como membro efetivo do IHGRGS. Porto Alegre. Disponível em: $<$ http://www.ihgrgs.org.br/artigos/Gunter_Brasil_Africa.htm $>$. Acesso em: 25 mar. 2010. p. 16).

${ }^{38}$ WEIMER, Günter. Inter-relações arquitetônicas Brasil-África. 2008. 40p. Pronunciamento de Posse como membro efetivo do IHGRGS. Porto Alegre. Disponível em: <http://www. ihgrgs.org.br/artigos/Gunter_Brasil_Africa.htm>. Acesso em: 25 mar. 2010. p. 16.

${ }^{39}$ OLIVER, Paul. Encyclopedia of vernacular architecture of the world. Cambridge; New 
York, NY, USA: Cambridge University Press, 1997. 2384 p.

${ }^{40}$ VLACK, op. cit.

Artigo recebido em novembro de 2011. Aceito em dezembro de 2011. 